\title{
FAZER A ÁGUA CIRCULAR: TEMPO E ROTINA NA BATALHA PELA HABITAÇÃO
}

Camila Pierobon ${ }^{1}$

${ }^{1}$ Centro Brasileiro de Análise e Planejamento, São Paulo, SP, Brasil

\section{Prelúdio ${ }^{1}$}

Em maio de 2018, Leonor foi surpreendida em sua casa com uma operação da polícia civil. Ela fora informada de que seria investigada por cobrar "taxas ilegais" dos moradores da ocupação popular onde ela vivia. De fato, à época, Leonor exercia a função de cobrar dos moradores o valor referente ao consumo da água e pagar a conta, posição alcançada mediante uma eleição interna. Com apenas um hidrômetro para 80 famílias, a conta refletia o valor total da água consumida pelos moradores do prédio e este valor era posteriormente dividido entre os apartamentos. Naquele mês específico, a bomba elétrica que transportava água da cisterna para a caixa d'água da ocupação havia queimado. Assim, junto aos R\$ 12 referentes à conta de água, Leonor também cobrou a taxa de $\mathrm{R} \$ 15$ de cada apartamento para que eles pudessem comprar uma nova bomba. Para comprovar o recebimento do dinheiro, Leonor elaborava manualmente os recibos em duas vias. Os policiais solicitaram para averiguação a via referente aos recibos da água e da taxa que ficavam com Leonor. Para ela, os moradores que "não queriam pagar" pelo uso da água a haviam denunciado na tentativa de tirá-la da função de cobradora. Sua indignação me foi descrita com as seguintes palavras: "é inacreditável, depois de velha ser enquadrada por fazer as coisas certas". 
A operação da Polícia Civil na ocupação onde mora Leonor foi efeito do incêndio e posterior desabamento do edifício Wilson Paes de Almeida, no largo Paissandu, cidade de São Paulo. Ocorrido no dia $1^{\circ}$ de maio de 2018, o incêndio deixou sete mortos e dois desaparecidos. O drama das famílias que perderam suas casas e o momento exato da perda de vidas foram transmitidos ao vivo em rede nacional e provocaram o debate público em torno da segurança e dos riscos das ocupações organizadas por movimentos populares e da responsabilidade do estado diante da tragédia. Com um tom acusatório e criminalizador, as falas que denunciavam a cobrança de "taxas ilegais" para se viver no local foram ampliadas sem contestação. Também foi bastante visibilizada a precariedade das instalações infraestruturais com foco na energia elétrica e no uso ilegal da eletricidade, cujo discurso atribuía aos moradores a responsabilidade pelo incêndio. O evento ocorrido em São Paulo e a forma como se construiu a discussão pública tiveram reverberações imediatas nas ocupações populares da cidade do Rio de Janeiro.

Assim que a polícia deixou a casa de Leonor, ela me ligou bastante nervosa e com a diabetes alterada. Aos 60 anos, ela estava apreensiva e com medo, visto que ela não poderia pagar um advogado que a defendesse. Eu, então, busquei ajuda junto ao presidente da Comissão de Direitos Sociais e Interlocução Sociopopular (CDSIS) da Ordem dos Advogados do Brasil $(\mathrm{OAB} / \mathrm{RJ})$ cujo contato advinha do trabalho jurídico que eles faziam na defesa da ocupação como habitação popular e coletiva em parceria com o Núcleo de Terras e Habitação (NUTH), da Defensoria Pública do Estado do Rio de Janeiro. Em maio de 2018 fazia sete anos que Leonor e eu havíamos nos tornado amigas, o que me permitiu etnografar seu cotidiano (Pierobon 2018). Ofereci-me para ser sua testemunha de defesa caso um processo acusatório fosse movido contra ela. Por sorte, a ameaça do processo não se concretizou como um evento, mas produziu efeitos concretos em sua vida. Por viver em uma área controlada por uma facção de tráfico de drogas, Leonor foi ameaçada pelos jovens traficantes, que a acusavam de ter feito uma aliança com a Polícia Civil. Felizmente, ela conseguiu "desenrolar" essa suspeita. 


\section{Introdução}

Os problemas relativos à habitação que envolvem os pobres urbanos são, como afirma Appadurai (2013), "um verdadeiro campo de batalhas". ${ }^{2}$ Nas últimas décadas temos acumulado pesquisas que se dedicam a entender as batalhas que as populações pobres travam pela habitação, seja nas ciências sociais, nos programas de planejamento urbano, ou nos estudos demográficos, entre outros. No caso brasileiro, e especificamente na cidade do Rio de Janeiro, as favelas foram o lócus privilegiado dos estudos sobre pobreza e habitação popular (Zaluar \& Alvito 2006; Valadares 2005). Entretanto, a forte retomada das políticas de remoções na última década e o surgimento de programas sociais direcionados à moradia, como o "Morar Carioca", o "Minha Casa Minha Vida", além do "Programa de Aceleração do Crescimento", ampliaram as discussões sobre as batalhas pela habitação entre os pobres urbanos (Cavalcanti 2017; Conceição 2016; Barros 2016; Lobo 2015; Gutterres 2014; Magalhães 2013). Soma-se a isto ainda a instalação de unidades de policiamento militar no interior das favelas (UPPs) e os usos do Exército na coprodução dos espaços urbanos, o que modificou os modos de habitar a cidade (Franco 2018; Davies 2017; Menezes 2015; Leite 2012). Na última década, também houve um número importante de ocupações de imóveis e loteamentos de terras organizados por segmentos populares que trouxeram para a esfera pública a pauta do "direito à cidade" para as populações pobres (Cortado 2018; Silva 2017; Fernandes 2013).

No cenário internacional, muitos pesquisadores têm ampliado os estudos sobre as batalhas pela habitação a que estão submetidos os pobres urbanos por meio das análises das infraestruturas que fazem as cidades. Os trabalhos sobre a distribuição desigual e as consequentes disputas pela água potável (Anand 2017a; Ranganathan 2016; von Schnitzler 2016), energia elétrica (Pilo 2020; Schwenkel 2018; Boyer 2015) ou saneamento básico (Lancione \& McFarlane 2016; Brown 2014; Desai et al. 2014), por exemplo, têm aberto caminhos para trabalharmos questões antropológicas fundamentais, como afetos e conflitos; esperanças e imaginações; modernidade, desenvolvimento e temporalidade; produção de Estados e de mercados, do público e do privado, do formal e do informal (Appel et al. 2015) e, aqui incluo, do legal, do ilegal e do ilícito (Telles 2010). Outros autores têm tensionado essa discussão, mostrando como as infraestruturas são centrais nas guerras urbanas que envolvem grupos armados, como mafiosos e paramilitares, bem como as relações destes com agentes do estado (Muehlmann 2019; Ranganathan 2014; Graham et al. 2013). O argumento base destes textos é que as infraestruturas são o substrato da vida urbana e estudá-las é entender os ritmos da vida cotidiana por um outro ângulo. 
Em diálogo com a bibliografia que toma as "infraestruturas" como objeto etnográfico, este trabalho tem como fio condutor a batalha de Leonor para garantir o abastecimento de água em sua casa, o que é indissociável da sua luta para assegurar o fornecimento de água na habitação popular onde vive. O trabalho individual de Leonor está emaranhado com o trabalho coletivo de fazer a água circular no decorrer dos quinze anos de existência da ocupação. Veremos como o esforço de Leonor para garantir o abastecimento de água em sua casa congrega a luta política da ocupação pelo direito dos pobres viverem no centro da cidade, a batalha das famílias para manterem os ritmos e a rotina de suas vidas diárias, e a guerra que envolve agentes do estado e do tráfico de drogas no cotidiano da ocupação. Parto do pressuposto de que o acesso à água não está garantido aos pobres urbanos. Ao contrário, a água é alvo constante de disputas. Para se acessar este bem vital, é necessário um árduo esforço físico, social e político desenvolvido individualmente e pelos coletivos em que cada um está inserido.

Acompanhar os esforços de Leonor para garantir o abastecimento de água em sua casa nos ajuda a compreender a centralidade das pessoas comuns nos processos de fazer as infraestruturas funcionarem (Simone 2004). Por meio das ações de Leonor, trago as experiências concretas vividas pelos pobres urbanos que constantemente improvisam linhas de fuga diante de caminhos estreitos. Tornar a vida possível entre os pobres urbanos significa construir rotinas em contiguidade com reformas e ruínas ininterruptas (Scott 1998; Gupta 2018), com o trânsito entre o legal, o ilegal e o ilícito (Telles 2010), e com a ilegibilidade das práticas de estado (Das 2004). O que descrevo abaixo são as maneiras com que pessoas e grupos urbanos vulneráveis criaram possibilidades para continuar suas vidas ao lidarem com e reagirem às condições que os criminalizavam e os tornavam ainda mais precários (Lancione \& McFarlane 2016).

O texto traz uma perspectiva generificada da experiência de se viver em uma ocupação popular na cidade do Rio de Janeiro e analisa o lugar das mulheres na batalha para garantir a habitação. Para isso, centro-me nos problemas cotidianos enfrentados por Leonor. Estes problemas me foram narrados no interior da relação de amizade e "confiança mútua" que estabelecemos ao longo de sete anos (Das 2015). Gênero é central para compreendermos a importância do trabalho manual feito pelas mulheres para garantir os ritmos e a rotina da vida diária. O enquadramento do trabalho está no "cotidiano" (Das 2007) e nas ações realizadas pelas mulheres para manterem a vida social diante da instabilidade que caracteriza suas vidas. Garantir o abastecimento de água é fazer uma gestão do tempo que, para as mulheres, significa organizar o dia entre cozinhar e lavar a louça, 
dar banho em crianças e/ou idosos, limpar a casa, entre tantos outros afazeres domésticos e além deles. A instabilidade do fornecimento de água produz uma quebra constante de rotina que as atinge visceralmente. Tempo é um agente que importa para compreendermos como o problema do acesso à água é construído socialmente. Há um trabalho feito ao longo do tempo por Leonor e seus vizinhos para manterem a circulação de água em suas casas. Inspirada nos trabalhos de Veena Das (2007, 2014, 2015), descrevo os esforços de Leonor para garantir o abastecimento de água em sua casa como uma maneira de fazer o ordinário aparecer.

Os caminhos postos em prática por Leonor e seus vizinhos para fazerem a água circular borram as fronteiras analíticas que distanciam o público do privado. Em diálogo com a perspectiva que analisa "a mútua constituição entre gênero e estado" (Vianna, Lowencron 2017), descrevo a porosidade das diferentes escalas de atuação do estado na construção da vida íntima e doméstica de Leonor. Ocorre que, no cotidiano, as práticas estatais se realizam em conexão com os agentes armados que controlam o território. Trago a atuação desses grupos armados entendendo-os como uma das formas de "guerra infraestrutural" (Mbembe 2003), em que agentes do tráfico de drogas se infiltram na vida cotidiana por meio das infraestruturas. Estado e tráfico, na perspectiva de Leonor, aparecem como agentes masculinos que controlam o território, cujas consequências recaem de modo específico no cotidiano das mulheres. O governo do território e das pessoas que nele vivem se dá por meio do controle dos objetos e dos materiais que tornam a vida possível. Apresentar a vida social da água nos interstícios dos poderes do estado e do tráfico de drogas torna visível o funcionamento desses atores e amplia a discussão sobre violência urbana. As texturas das relações cotidianas que garantem a continuidade da vida social são trabalhadas em conexão com os macro e micropoderes que atualizam as desigualdades no mais ordinário da vida: a água.

\section{Tirar entulhos, reformar canos}

A Ocupação Nelson Mandela surgiu em 2004 por meio de movimentos sociais libertários e anarquistas que lutavam pelo direito de os pobres urbanos morarem no centro da cidade, local com maior infraestrutura de transporte e saúde e melhores oportunidades de trabalho (Fernandes 2013). Somado ao projeto político, as famílias que vieram a ocupar o imóvel compreendiam a ocupação como uma forma de deixar de pagar aluguel, ou ainda, de sair de localidades controladas por grupos armados como milícias ou traficantes de drogas. Com o sonho de se construir uma ocupação socialista, 
libertária e autogestionária, moradores, membros de movimentos sociais, defensores públicos, vereadores específicos e apoiadores diversos, em especial estudantes e professores de universidades públicas, se engajaram na transformação de um prédio abandonado pelo poder público há 20 anos em um espaço de moradia para 80 famílias de baixa renda (Fernandes 2013; Birman et al. 2014; Pierobon 2018).

Diferente de ocupações de terras, o imóvel abandonado tinha uma infraestrutura preexistente que conectava a Ocupação com a história do prédio e também com a história da cidade e do país. No caso específico, o prédio foi originalmente construído para ser um hotel que receberia funcionários do Instituto Nacional de Colonização e Reforma Agrária (Incra). Por isso, embora os quartos ${ }^{3}$ fossem considerados pequenos pelos ocupantes por medirem entre 30 e $40 \mathrm{~m}^{2}$, eles tinham as instalações de rede elétrica e também encanamentos para a circulação de água e esgoto. Contudo, sem usos, reparos e manutenções, não é difícil imaginar que o tempo corroeu os canos de ferro que transportavam os líquidos limpos e sujos pelo prédio. O mesmo ocorreu com as fiações elétricas. As paredes também perderam o emboço. Pedaços das paredes e do teto que ano após ano caíam pelo chão encheram quartos e corredores de entulhos. Embora ninguém vivesse no prédio, ele não era um espaço vazio. Junto ao lixo que era depositado no local por transeuntes, formou-se um ambiente propício para a proliferação de insetos e roedores.

Para transformar este prédio em uma ocupação de moradia para famílias de baixa renda foi necessário árduo trabalho braçal de homens e mulheres, que subiam e desciam 13 andares de escadas com sacos de cimento, tijolos, canos e outros materiais. Também houve investimento financeiro de trabalhadores informais, cujo orçamento doméstico era incerto. Nos primeiros dias de ocupação, os moradores dividiram por gênero as tarefas que transformariam as ruínas do antigo hotel do Incra em habitação coletiva. Nesta divisão generificada do trabalho que marcou o início conflituoso da ocupação, os homens ficaram encarregados de consertar e conectar as fiações elétricas e de desentupir e reparar os encanamentos de água e esgoto. As mulheres foram responsáveis pela limpeza das áreas comuns e por preparar as refeições coletivas durante os intensos dias de trabalho.

Além de retirar os entulhos, limpar as áreas comuns significava lavar os banheiros coletivos. Aqui se instaurava o conflito: as mulheres acusavam os homens de não realizarem de forma adequada o seu trabalho e sujarem os locais que elas já haviam limpado. Mas o mais difícil era lavar os banheiros. As narrativas femininas falam de fezes nas paredes deixadas de propósito como retaliação por algum desentendimento, além do odor e dos espirros de urina. Embora tenham ocorrido em 2004, essas histórias fundacionais da 
ocupação não desapareceram, ao contrário, elas são compartilhadas entre as mulheres que participaram desse período e são constitutivas das suas relações. Nos anos posteriores, essas experiências foram acionadas sempre que se instaurava algum conflito, ao mesmo tempo em que se acumulavam, pois, a regra social que responsabiliza as mulheres pelo cuidado com os espaços coletivos se repetia, não sem resistência. ${ }^{4}$

Desentupir, reparar e limpar os canos de água e esgoto em um prédio de 13 andares não foi tarefa fácil. Para levar água aos apartamentos, foi necessário conectar a tubulação pública ao encanamento do prédio que enche a cisterna da ocupação. Essa conexão, irregular aos olhos do estado, porém vital para os recém-ocupantes, foi fundamental para que os novos moradores pudessem se instalar e permanecer no prédio. Ao mesmo tempo, foi necessário desentupir e consertar as colunas de água que ligavam a cisterna da ocupação à caixa d'água do prédio, bem como limpar cada um dos reservatórios. Para que a água caminhasse em direção oposta à gravidade era preciso uma bomba d'água que exige o funcionamento de outra infraestrutura: a energia elétrica. Para o motor funcionar, foi feito um "gato", uma conexão ilegal na fiação elétrica que conectava o prédio à fiação da empresa privada que fornece energia na cidade. Também foi preciso desentupir e reparar os canos que conectam as colunas coletivas de água aos apartamentos domésticos. Até aqui, como me narraram alguns moradores, todo o trabalho foi feito de forma coletiva. Por fim, cada família consertou os canos de seus próprios apartamentos à sua maneira: uns com a ajuda de algum vizinho ou contratando o serviço de um técnico, outros utilizando sua própria força de trabalho, todos utilizando seus escassos recursos. No início da ocupação, o trabalho de fazer a água circular fundou uma forma particular de associação e solidariedade entre os moradores, mesmo que conflituoso.

Desde a sua fundação, "a água" se tornou um problema constante no cotidiano dos moradores da ocupação. Sem auxílio estatal e com recursos limitados, as obras estruturais para substituir as antigas colunas de ferro corroídas pelo tempo nunca foram realizadas. Os vazamentos de água pelas paredes do prédio eram constantes. Cabia aos moradores improvisar soluções para um problema urgente que logo se repetia e gerava novas urgências, conflitos e acusações. Não era diferente com a energia elétrica. Com instalações precárias, os curtos-circuitos eram frequentes. Não raro, o eletrodoméstico adquirido com dificuldade queimava. Outras vezes os curtos-circuitos geravam princípios de incêndio. A precariedade da fiação também dificultava que os moradores instalassem chuveiros elétricos. Para tomar banho quente, era necessário aquecer baldes de água em fogões cuja fonte de energia era o botijão de gás, que tinha alto 
custo para as famílias. Outra alternativa era utilizar um esquentador elétrico de água, que demandava menos energia que um chuveiro, mas exigia tempo dos ocupantes. À época, alguns moradores criaram uma comissão para fiscalizar aqueles que instalavam chuveiros elétricos. Aqueles que os instalavam eram acusados de sobrecarregar a fiação do prédio e de serem os responsáveis pelos curtos-circuitos.

\section{Regularizar a água}

Assim que a água começou a circular pelas colunas e pelos canos do prédio, ainda em 2004, os moradores buscaram o apoio de um coletivo de advogados ativistas que atuam na defesa de causas populares para regularizar o abastecimento de água e o fornecimento de energia elétrica. Nos processos que os moradores guardam em suas casas, é possível ler que esses advogados acionaram judicialmente a Companhia Estadual de Água e Esgoto (Cedae) e solicitaram, além da regularização, a "tarifa social", benefício oferecido pela Cedae junto com o governo do estado do Rio de Janeiro que subsidiam parte do consumo de água para famílias de baixa renda. Após dois anos de negociações, a regularização e a tarifa social foram formalizadas. Em audiência pública realizada no dia 19 de janeiro de 2006, foi acordado que os moradores da ocupação seriam os responsáveis pelo pagamento da conta de água a partir desta data. Contudo, a conta de água ainda viria registrada em nome do Incra, visto que os moradores não tinham a titularidade do imóvel. Ficou determinado também que as dívidas do consumo de água anteriores a 2006 seriam de responsabilidade do Incra. Vinte anos de vazamentos de água produziram uma dívida considerável.

Embora tenham comemorado, a decisão não agradou totalmente os moradores. Antecipando conflitos em torno do pagamento das contas, os moradores solicitaram a instalação de hidrômetros em cada um dos apartamentos para que cada família ficasse responsável pelo pagamento de sua própria conta de água. Mas isso não ocorreu. Ao contrário, com apenas um hidrômetro para 80 apartamentos, inaugurou-se uma nova ordem de conflitos.

O mesmo coletivo de advogados também acionou a empresa privada Light para regularizar o fornecimento de energia elétrica. Dessa vez, com o suporte dos técnicos do Instituto de Terras e Cartografia do Estado do Rio de Janeiro (Iterj), órgão público que executa a política fundiária do estado, houve um acordo no qual o Iterj ficou responsável pelo pagamento das contas de luz decorrentes do uso de energia elétrica. Técnicos do Iterj e os advogados 
ativistas foram pessoas-chave no processo de regularização, atuando como mediadores entre a empresa privada e os ocupantes. Este acordo ocorreu após muitos meandros. Nos dois anos de negociações, funcionários da Light fizeram inúmeras vistorias-surpresa no prédio. Na leitura dos moradores, essas vistorias eram uma tentativa de flagrar o uso irregular de energia e suspender o processo de regularização. Para não serem pegos, os moradores desenvolveram a seguinte estratégia: para que os fiscais não pudessem ver as luzes acesas no prédio, os moradores fechavam as janelas direcionadas à rua com materiais densos que impediam a passagem de luz.

Regularizar o fornecimento de água e eletricidade fez com que os moradores do prédio se engajassem nos processos da lei e da burocracia (Das \& Walton 2015) para garantir a habitação como projeto político, para manter a casa como cotidiano e a infraestrutura como direito a bens vitais. Junto com outras demandas feitas aos órgãos estatais, ano após ano, os conhecimentos sobre o funcionamento do estado e das leis se acumulavam, tornando-se capital político na batalha pela casa e pela habitação. Como no caso da regularização de energia elétrica analisado por Veena Das e Michel Walton (2015), longe de evitar os olhos do estado, os moradores da ocupação exigiam sua entrada na vida pública como cidadãos com o direito de viver na cidade legalizada. Nesse sentido, a luta pelas infraestruturas é, muitas vezes, a forma concreta com que as populações pobres reivindicam um bem como público e como um direito. Os moradores buscaram a lei e desenvolveram habilidades para lidar com as burocracias estatais e privadas, embora soubessem que seu uso é incerto e cheio de perigos (Das 2007).

É interessante observar que os processos que levaram à regularização do abastecimento de água e de eletricidade na ocupação tiveram decisões distintas, o que nos permite pensar a heterogeneidade das práticas estatais e sua produção de ilegibilidades (Das 2004, 2007). Essa heterogeneidade, muitas vezes arbitrariedade, dificulta a leitura de suas regras e regulamentos. Enquanto, através de um acordo, o governo do estado garantiu o pagamento do consumo de energia elétrica ao fazer a transferência direta de dinheiro público para a empresa privada Light, sem que nenhum morador tivesse acesso ao valor dessas contas, foi decidido em audiência pública que os moradores seriam responsáveis por pagar o consumo da água diretamente na sede da empresa pública Cedae. Na vida doméstica dos ocupantes, o acordo público entre Iterj e Light fez com que os problemas relativos à energia elétrica permanecessem os mesmos: curtos-circuitos constantes, as chances de perda de eletrodomésticos e possíveis princípios de incêndio. Em paralelo, o consumo, a divisão da dívida, a cobrança do dinheiro, o pagamento das contas de água e a elaboração manual de recibos talvez tenham se tornado o maior ponto de tensão entre os moradores da ocupação. 
Embora a formalização jurídica da moradia tenha ocorrido apenas no ano de 2012, a legalização da água e da eletricidade ocorreram em 2006. Em alguma medida, a regularização do fornecimento reconhecia a moradia dos ocupantes: água e eletricidade geraram documentos que se tornaram políticos nas mãos daqueles que lutavam por sua permanência no prédio. Contudo, a regularização não impediu que o fornecimento de água e energia elétrica se desse de forma precária. Nos dez anos de trabalho de campo na Ocupação Nelson Mandela, de modo geral, e nos sete anos fazendo parte do cotidiano de Leonor, eu testemunhei ações estatais "ilegíveis" (Das 2004) e "autoritárias" (Roitman 2005), como cortes ilegais no abastecimento de água e eletricidade, cobranças ilegítimas de dívidas anteriores ao momento da ocupação e, eventualmente, o abastecimento de água da região misturada ao esgoto.

\section{Canos, paredes e vizinhos}

As conexões que transformaram um prédio vazio em residência para famílias de baixa renda passaram por esforços coletivos nas instalações e nos reparos das infraestruturas. No plano doméstico, apresento o trabalho de Leonor para transformar um quarto de hotel abandonado em sua "casa" (Araujo 2017). Quando Leonor se mudou de Santa Cruz, Zona Oeste da cidade, para a ocupação, no final de 2004, a água e a eletricidade já chegavam aos apartamentos. Após a distribuição dos quartos que seguiu o princípio ético de que os idosos ou aqueles com dificuldades de locomoção teriam preferência nas escolhas, um apartamento ficou vago no $11^{\circ}$ andar. À época, Leonor tinha 45 anos. Naquele momento, subir e descer onze lances de escadas, visto que os elevadores foram furtados durante o período em que o prédio ficou sem uso, não era um impeditivo para ela. Mas o quarto estava sem porta, muita água escorria pelas paredes, a rede de fiação elétrica estava danificada, havia entulhos por todos os lados. Ao ver o quarto, Leonor teve dúvidas se moraria naquele espaço. Contudo, os conflitos familiares, as agressões físicas e a morte de seu filho primogênito não permitiam que ela retornasse para sua antiga casa (Pierobon 2018). Como ela vendia "remédios naturais" na rodoviária da cidade próxima à ocupação, a possibilidade de morar ao lado do ponto de trabalho - e, com isso, melhorar suas condições de vida - fez com que ela decidisse ficar. Em suas palavras, "a quitinete era horrível, mas o lugar era bom". 
Mudar para um local sob as condições descritas acima exige reflexões sobre infraestrutura, sobre esforço físico, mas também sobre solidariedades e conflitos familiares, de amizade e de vizinhança. A princípio, seus filhos não quiseram deixar o bairro na Zona Oeste e se mudar para a ocupação. Então, Leonor decidiu fazer o trabalho sozinha. Para eliminar os entulhos, ela encheu dezenas de sacolinhas plásticas e as colocava no corredor. Mesmo com a ajuda dos vizinhos, foram necessários dez dias para descer com todo o entulho nos braços. Ela rapidamente foi atrás de uma porta. Com "pavor" de imaginar alguém espiando sua intimidade, um amigo lhe deu uma porta velha que, com a ajuda dos vizinhos, foi instalada. Na sequência, Leonor comprou um vaso sanitário. Como o encanamento de esgoto já existia, desentupi-lo foi tarefa relativamente fácil. A descarga acoplada havia sido furtada e ela não tinha dinheiro suficiente para comprar uma nova. Para se desfazer de fezes e urinas, Leonor enchia baldes de água e os jogava no vaso sanitário. Aágua escorria pelas paredes e pelo teto. No chão do apartamento se formava uma poça d'água contínua. Para entrar na casa, Leonor fez uma elevação com tijolos e tábuas de madeira para poder atravessar o quarto sem que os pés ficassem encharcados. Ela, então, começou a trazer seus móveis para o centro do Rio de Janeiro.

Sem condições de pagar um caminhão de mudança, Leonor foi aos poucos transportando de ônibus os objetos que transformariam o quarto em sua casa: fogão, botijão de gás, panelas, roupas, sapateira, televisão, vassoura. Vez ou outra, um vizinho a ajudava a carregar os pertences de sua antiga casa até o ponto de ônibus. Ela, então, subia no transporte público, viajava 60 quilômetros e depois carregava os objetos até o $11^{\circ}$ andar da ocupação. Alguns moradores se recusaram a ajudá-la alegando que ela tinha filhos que poderiam fazer isso, mas, em conflito com os filhos, eles não a auxiliavam com a mudança. Felizmente, um colega da Igreja Batista que ela frequentava ofereceu seu caminhão para que ela pudesse finalizar a mudança. Nessa última viagem, vieram os armários, a mesa de pedra, a geladeira e outros móveis pesados. Com a ajuda dos vizinhos, os móveis chegaram no apartamento. Ela não pôde trazer sua máquina de lavar para a nova casa, pois a instalação elétrica não suportava a energia necessária para o eletrodoméstico. Leonor se mudou para a ocupação em 2004, mas só deixou de lavar as roupas na mão em 2015.

Na tentativa de resolver o problema dos vazamentos de água, ainda no início da ocupação, Leonor pediu a alguns moradores-encanadores que a ajudassem a encontrar uma solução. Após analisá-los, todos disseram a ela que seria necessária uma obra para resolver o problema. Com "dificuldades de ter dinheiro até para comer", ela não tinha condições financeiras para 
a compra de materiais e para o pagamento da mão de obra. Nas primeiras semanas de ocupação vieram as primeiras decepções: alguns vizinhos ofereceram sacos de cimento para resolver o problema dos vazamentos, mas os sacos nunca chegaram. A instalação elétrica feita por "gatos", extensões improvisadas e pequenos fios pendurados, poderia encostar na água a qualquer momento, o que deixava Leonor em constante tensão.

Na casa havia apenas uma saída de água, um cano localizado no banheiro, especificamente onde outrora havia sido um chuveiro. Os vazamentos da casa de Leonor também chegavam ao apartamento abaixo do dela e causavam conflitos de vizinhança. Tudo piorava quando Leonor precisava usar a água em sua casa. Para não ter problemas com a vizinha, ela cortou e grampeou várias garrafas pet em sequência e montou uma espécie de calha para conduzir parte dos seus vazamentos para o ralo que ficava no banheiro. Durante todo o tempo em que ficou neste apartamento, Leonor não conseguiu resolver o problema dos vazamentos e viveu os primeiros meses com o chão encharcado, caminhando sobre as pequenas pontes montadas em casa. O que fica evidente são os arranjos cotidianos com que as infraestruturas são feitas e refeitas e nos mostram suas implicações domésticas e sempre coletivas. A análise das relações que permitem que as infraestruturas funcionem implica as densas experiências corpóreas e as complexidades das relações afetivas entre vizinhos, que são inseparáveis da gestão desigual da água pela cidade (ver Quintslr 2018).

Pouco tempo depois, Leonor se mudou para um apartamento que vagou no oitavo andar. Seus dois filhos adolescentes passaram então a viver com ela. Após uma acirrada discussão em assembleia, ela conseguiu a aprovação para que seu outro filho, Silvio, viesse morar com sua esposa e filhos em um apartamento que vagara na ocupação. Leonor ficou feliz, pois ela e seus três filhos estavam juntos novamente. Mas o oitavo andar ainda era ruim para ela. Nesse quarto, como no anterior, era impossível que sua mãe idosa a visitasse devido à sua dificuldade de locomoção. Para diminuir o número de escadas e poder receber a visita de sua mãe, Leonor negociou uma troca de apartamentos com um vizinho. Em 2008 ela foi morar no terceiro andar, onde se fixou.

No entanto, outros problemas apareceram: as paredes tinham perdido o emboço. Sem o emboço, não havia a vedação do apartamento e, assim como os tijolos, a sua vida íntima e a dos vizinhos ficavam expostas. Os anos de ausência de emboço favoreceram a proliferação de carrapatos, cujos ovos eram depositados nos tijolos. Também havia pulgas. Estas se reproduziam nos vãos dos velhos tacos de madeira que o tempo corroeu. Num primeiro momento, Leonor tentou eliminar as pulgas e os carrapatos jogando água 
fervendo no chão e nas paredes, sem sucesso. Com o dinheiro do trabalho informal, Leonor aos poucos emboçou as paredes de sua casa e resolveu tanto o problema com os vizinhos como o dos carrapatos. Para acabar com as pulgas, ela arrancou os tacos de madeira com as mãos, deixando o chão no cimento. Mas o cimento fazia com que levantasse muita poeira em seu apartamento. Para varrer o chão sem que a poeira levantasse, era preciso jogar água antes de varrer.

Durante anos de esforço e dedicação, Leonor foi reformando sua casa. Ela trocou as fiações elétricas e instalou tomadas, colocou tanque no banheiro e pia na cozinha, instalou um chuveiro elétrico. Ao mesmo tempo, seus filhos cresciam e, já adultos, entre 2007 e 2009, os dois filhos que moravam com ela se mudaram para São Paulo após deixarem a prisão, por sofrerem ameaças devido à sua relação com o tráfico de drogas. Silvio continuou sendo seu vizinho. Quando Leonor conseguiu um dinheiro extra, já em meados de 2013, ela comprou piso frio para diminuir a poeira. Contudo, o dinheiro permitiu que ela colocasse piso frio apenas na sala. O próximo dinheiro que ela conseguisse seria destinado à finalização da cozinha. Em 2014, 2015 e 2016 eu pude acompanhar os esforços de Leonor para reformar o banheiro, comprar armários embutidos para a cozinha e pintar as paredes de seu apartamento. Mas a descarga ela não conseguiu consertar e continua jogando baldes de água no vaso sanitário. O que começou com sacos de areia, poeira, entulho, água vazando pelas paredes, ano a ano foi se tornando a casa de Leonor.

Nas primeiras partes do texto, eu mostrei como a transformação de um prédio recém-ocupado com habitação popular passou pela instalação, a reforma e a manutenção das infraestruturas, cujos efeitos são concretos, mundanos e nada banais (Star 1999). A árdua batalha para a reforma e a manutenção da casa leva tempo e exige investimento financeiro, físico e emocional continuado, que é, ao mesmo tempo, individual e coletivo. Nas descrições acima, é possível perceber como as infraestruturas conectam materialmente a vida íntima das famílias, a vida coletiva do prédio e a vida pública na cidade (Anand 2017a; von Schnitzler 2016). Apoiada nos autores citados ao longo do texto, defendo que a batalha pela habitação à qual estão submetidos os pobres urbanos caminha par a par com o trabalho cotidiano infindável de fazer as infraestruturas funcionarem. Embora eu tenha descrito o esforço de Leonor no processo de transformar um quarto abandonado em sua casa, esse empenho está presente em todas as famílias, cada uma com suas possibilidades. Quando o fantasma da remoção chega, as memórias do árduo trabalho, do investimento financeiro de anos e todas as relações que possibilitaram a construção da casa são acionadas para se dizer: "é aqui onde eu quero ficar". 


\section{Cobrar a água: ritmos da vida diária}

Com o passar dos anos, Leonor se tornou uma liderança no interior da ocupação. Sempre presente em reuniões e assembleias, ela era assertiva na vida política do prédio, na tentativa de encontrar soluções para os problemas que interferiam em sua rotina doméstica. Sua liderança emergia de seu engajamento na luta pública para assegurar o abastecimento de água no prédio e na batalha com outros moradores para pagar a conta e assim garantir os ritmos da sua vida cotidiana. A partir de 2014, Leonor, agora com 55 anos, se tornou a responsável pelo cuidado de sua mãe idosa e doente, passando a ter uma intensa vida dentro de casa. Se a intermitência da água era algo que tornava seu dia a dia difícil, porém contornável, desde a chegada da mãe a regularidade do abastecimento de água passara a ser, literalmente, vital.

Não é difícil imaginar que eram as mulheres que tinham que lidar com os problemas relativos à água, bem essencial à vida de uma casa (Anand 2017a). Muitas mulheres passavam a maior parte do dia em casa, sendo este espaço também o seu lugar de trabalho. Por isso, elas viviam a precariedade cotidiana das instalações infraestruturais de forma singular. Majoritariamente trabalhadoras informais, suas casas eram os locais onde elas costuravam roupas, cozinhavam refeições que seriam vendidas aos trabalhadores da região, cuidavam dos filhos e dos idosos das suas famílias e das pessoas que trabalhavam nas ruas da Central do Brasil, e para onde levavam seus clientes e/ou parceiros sexuais. No dia a dia, eram as mulheres que lidavam com a tubulação de água quebrada, com a queima da bomba da caixa d'água e com as burocracias "ilegíveis" (Das 2004) e "autoritárias" (Roitman 2005), como o corte ilegal da energia elétrica, as cobranças indevidas do consumo de água, as vistorias-surpresa de agentes do estado, o fornecimento de água contaminada.

Como escrevi acima, a regularização do abastecimento de água ocorrida em 2006 inaugurou um dos maiores conflitos entre os moradores da ocupação: o pagamento da conta de água. O consumo, a dívida, a cobrança, o pagamento da conta de água e os recibos se tornaram uma fonte de ansiedade permanente e incerteza generalizada (von Schnitzler 2016). Ano após ano, os diversos conflitos em torno do pagamento da conta desgastaram relações entre os moradores, tornando algumas delas intransponíveis. Com apenas um hidrômetro para 80 apartamentos, a solução para o pagamento da conta de água se deu da seguinte forma: por meio de eleições escolhia-se um morador responsável por receber R\$ 8 (em 2014) de cada família que vivia no prédio. Alguns moradores procuravam o cobrador, pagavam o valor e recebiam um recibo feito manualmente comprovando o pagamento. 
Outros não tinham dinheiro para pagar! Havia aqueles que se recusavam a pagar, pois entendiam que o abastecimento da água era um direito que deveria ser fornecido pelo estado. Essa dinâmica, que mudava mês a mês, fazia com que os cobradores criassem estratégias variadas para receber o dinheiro. Em meio às incertezas do trabalho informal, não raro o cobrador usava o dinheiro arrecadado para uso próprio, atrasando ou não pagando a conta de água. Essa ação gerava conflitos, acusações e novos grupos de pessoas se recusavam a pagar pela água. Por fim, todos sabiam que próximo do $15^{\circ}$ dia de cada mês o cobrador da água tinha com ele aproximadamente $\mathrm{R} \$$ 650. Isto fazia com que sua casa ficasse vulnerável, pois, não raro, as casas dos cobradores eram furtadas.

Em diversos momentos da história da ocupação, Leonor trabalhou como cobradora de água. Na tentativa de se diferenciar dos cobradores que foram acusados de "roubar o dinheiro da água", Leonor construiu sua legitimidade para a função cobrando os moradores de forma assertiva, pagando os boletos na data correta, redigindo os recibos do pagamento com assinatura e carimbo, e apresentando publicamente o comprovante de pagamento da conta de água. Sua construção de "honestidade" em nenhum momento significou "cordialidade". Essa categoria moral era compartilhada entre a maioria dos moradores e estes a apoiavam na função de cobrar a água, mesmo aqueles que se recusavam a falar com ela no dia a dia.

Como o atraso no pagamento das contas de água havia se normalizado na vida cotidiana do prédio, Leonor transformava o processo de cobrar o "dinheiro da água" em uma "declaração de guerra" (Roitman 2005). Ela colava cartazes pelos corredores para lembrar aos moradores que era a hora de pagar a água. Mais próximo do vencimento, Leonor fazia outro cartaz e expunha publicamente aqueles que ainda não haviam lhe dado o dinheiro da água, formando, assim, uma lista com o nome dos moradores que "deviam" e eram "ruins de pagar". Para cobrar dos homens que ofereciam alguma ameaça física a Leonor, ela pedia ajuda às "mulheres bravas, aquelas com cabelo nas ventas", para bater na porta dos apartamentos e cobrar o dinheiro. Se, na data do pagamento, um morador não tivesse levado o dinheiro a ela, à meia-noite estava Leonor batendo na porta da casa desse morador para pegar o "dinheiro da água". Essas ações fizeram com que ela ganhasse o apelido de bruxa, fosse chamada de insuportável, de filha da puta, entre outros tantos nomes. Mas nenhum desses xingamentos e apelidos feria a sua construção de "mulher honesta", característica que ela defendia com afinco. Desconfiada até de suas amigas no prédio e com medo de que roubassem o dinheiro "público" sem que ela tivesse condições de repor, Leonor mudava a cada dois dias o lugar onde ela escondia o dinheiro arrecadado. 
Essa relação pública com o recolhimento do dinheiro e o pagamento da conta de água está intimamente vinculada às dinâmicas de sua vida doméstica. Atrasar a conta de água e, com ela, a possibilidade de cortes, transformava completamente os ritmos do seu dia a dia. Como é impossível fazer a vida sem água, quando ela faltava, Leonor passava a comprar galões vendidos na região, o que pesava em seu orçamento doméstico. Outras vezes ela enchia seus galões nas residências dos amigos que viviam nos arredores. Mas o efeito de subir três lances de escadas carregando galões de 10 a 15 litros no braço produzia, ano a ano, desgastes e dores em seu corpo que também envelhecia. Assim, a batalha de Leonor para cobrar o dinheiro e garantir o abastecimento de água estava pautada em experiências corpóreas, na escassez do dinheiro e nos efeitos que a intermitência da água gerava nas rotinas e nos ritmos de sua casa.

O uso da água e o pagamento da conta eram, portanto, experiências necessariamente compartilhadas entre ocupantes. Esse ciclo mensal de consumo e dívida criava laços de obrigações e reciprocidades permanentes, tanto em relação ao estado e sua autoridade de cortar o abastecimento quanto entre os moradores do prédio. Na vida cotidiana, esse ciclo reforçava as alianças entre eles, mas também os conflitos, as dificuldades e as desigualdades entre aqueles que podiam e não podiam pagar. $\mathrm{O}$ enquadramento das ações dos moradores pagantes ou não pagantes é fundamental para entendermos como o problema é constituído localmente (von Schnitzler 2016). Analisar os usos da água no dia a dia é um caminho para dissolvermos a dicotomia público-privado e mostrar seus emaranhamentos. A água é uma das formas de o estado entrar na casa das pessoas, de construir temporalidades na vida íntima e doméstica (Anand 2017a), ao mesmo tempo em que é componente fundamental das relações de vizinhança. Por meio das rotinas que envolvem os usos da água entendemos mais um aspecto desse "campo de batalhas" (Appadurai 2013) que é garantir a habitação e a casa na vida cotidiana.

\section{Fantasma do despejo}

No ano de 2009, a cidade do Rio de Janeiro já havia sido escolhida para sediar a final da Copa do Mundo de Futebol, ocorrida em 2014. Naquele ano, houve o anúncio de que a cidade receberia também os Jogos Olímpicos de 2016. Desde então, um sem-número de projetos para "reformar e revitalizar" a cidade foram planejados. Para a região central do Rio de Janeiro estava prevista a instalação de uma Unidade de Polícia Pacificadora (UPP) no Morro da Providência e a "revitalização" intitulada "Porto Maravilha". 
Como os moradores mantinham vivas as memórias das experiências de remoções e despejos, muitos ficaram receosos com o que poderia acontecer. Quando se iniciaram os primeiros casos de remoção de famílias na localidade, os moradores da ocupação se assombraram e passaram a se dedicar com afinco à regularização fundiária da ocupação. Por meio de rede de relações continuadas com defensores públicos, ativistas, membros de movimentos sociais e partidos políticos, assistentes sociais, estudantes e professores universitários, dentre os quais eu me inseria, os moradores ganharam na justiça o direito de permanecer no prédio (Birman et al. 2014). Embora o fantasma da remoção assombrasse as relações de vizinhança (Gutterres 2016), ter garantias legais para manterem suas casas neste contexto foi uma vitória amplamente comemorada, mesmo que todos compartilhassem o medo de que esses ganhos pudessem ser revertidos.

Os efeitos das UPPs logo chegaram na ocupação. Mesmo sendo uma moradia popular localizada fora da favela, as políticas direcionadas a esses espaços transformaram os bairros próximos e as cidades adjacentes ao Rio de Janeiro (Miagusko 2016). Após a instalação da UPP no Morro da Providência e a prisão da liderança do tráfico de drogas na favela, que não eliminou o comércio ilegal, mas o reconfigurou (Menezes 2015), membros da facção local se viram forçados a procurar outros locais para suas atividades. As moradias populares localizadas nos arredores da favela se tornaram alvo propício para a instalação de novos pontos de venda de drogas. Dentre elas, estava a Ocupação Nelson Mandela. A expectativa de que a regularização fundiária garantiria a moradia dos ocupantes sofreu um forte golpe. A entrada do tráfico de drogas na ocupação enfraqueceu seu projeto político, criando um duplo medo: perder a habitação como sentido coletivo de reivindicações de direitos e perder a casa como espaço íntimo e doméstico. O prédio também passara a ser alvo de operações militares. O medo de morrer tornou-se parte do cotidiano dos moradores.

Embora regularizada, a invasão do tráfico de drogas reinseriu a ocupação na ilegalidade. Essa nova conjuntura poderia reverter o ganho jurídico, pois estava previsto no contrato de cessão de uso do imóvel que o governo do estado poderia suspender a regularização caso houvesse atividades ilegais ou criminosas no imóvel. Os moradores tentaram contornar a situação, sem sucesso. Foram inúmeras ações com o objetivo de denunciar a invasão perpetrada pela facção de tráfico de drogas, de algumas delas eu pude participar. A Polícia Militar era parte ativa na situação: em um primeiro momento, apoiou a invasão do tráfico e, depois, passou a receber os "arregos". 
Enfrentar abertamente dois poderes armados era perigoso demais para os moradores da ocupação. Se há poucos meses eles haviam comemorado a permanência no prédio em meio a remoções para a Copa do Mundo e as Olimpíadas, agora era um novo fantasma do despejo que passara a vigorar.

\section{Controle da água como garantia da moradia}

Logo após invadirem a ocupação e instalarem um ponto de venda de drogas em sua portaria, membros da facção do tráfico de drogas trouxeram suas namoradas e mesmo familiares para morarem na ocupação. Para isso, eles expulsaram antigos moradores dos seus apartamentos. Ouvi relatos de um morador que, não suportando a situação, "passou" seu apartamento para amigos ou familiares. Outro morador enfrentou abertamente os novos invasores, foi ameaçado e teve que deixar o prédio. Houve aquele que começou a consumir no ponto de vendas e, com o tempo, ficou devendo dinheiro para a facção. Este morador teve seu apartamento invadido e os pertences jogados pela janela. E, ainda, os quartos cujos titulares trabalhavam em obras fora da cidade foram tomados pelos jovens armados. Em pouco tempo, boa parte do espaço público do prédio passou para o domínio da facção. Embora aqueles que tinham sido inseridos no prédio por intermédio do tráfico de drogas tivessem relações de obrigações com estes e um maior status de poder nas dinâmicas locais, essas pessoas não eram, de fato, trabalhadoras do tráfico. Ao contrário, as famílias inseridas estavam na batalha para conseguir uma casa, que não necessariamente se desenvolve na luta pela habitação como projeto político. A entrada dessas famílias ampliou as divergências de concepções sobre o "morar" e sobre o que se pode reivindicar como direito coletivo. Para garantir a casa, esses novos moradores começaram o processo para regularizar a sua permanência no prédio. Uma batalha silenciosa entre novos e antigos moradores se iniciou.

Para regularizar a situação fundiária das famílias junto aos órgãos do estado é preciso gerar documentos que comprovem que a pessoa vive naquele local. Um dos documentos em que constatava a moradia eram, exatamente, os recibos referentes ao pagamento da conta de água. Assim, os papéis com assinaturas e carimbos feito manualmente pelo cobrador que comprovavam o recebimento do dinheiro da água, funcionavam como um atestado de moradia. Aqueles que desejavam regularizar sua situação junto ao Iterj, por exemplo, guardavam os recibos, que eram apresentados e, na sequência, se iniciava o processo de atualização das famílias que moravam 
no prédio. Francesca Pilo (2020) nos fala da importância de incorporarmos os documentos nas análises sobre infraestruturas, pois eles ligam vida íntima e doméstica com a vida pública e política.

No caso específico, os recibos estão inseridos em relações de poder nas quais, por um lado, temos a frágil materialidade de um documento produzido manualmente e, de outro, os poderes políticos e burocráticos que permitem a regularização da moradia. Os documentos produzidos pelos moradores da ocupação poderiam ser usados nos processos de regularização fundiária das novas famílias. Acima, destaquei que a regularização do fornecimento de água reconhecia a moradia dos ocupantes junto aos órgãos do estado. Agora mostro como práticas documentais do estado adquirem vida concreta no cotidiano dos moradores por meio de objetos frágeis. E é justamente este frágil papel que nos fornece a chave material para se pensarem as práticas e os poderes dos documentos em conexão com as infraestruturas e com a atuação de grupos armados na produção dos espaços urbanos (Benmergui \& Gonçalves 2019).

No momento em que os membros do grupo do tráfico de drogas invadiram a ocupação, Silvio, filho de Leonor, era o responsável por receber o dinheiro da água, fazer os recibos e pagar a conta. O gerente do ponto de venda de drogas começou a exigir de Silvio os nomes daqueles que não pagavam a conta de água em dia e também os recibos referentes ao pagamento da água para as famílias que foram introduzidas no prédio por intermédio da facção. Depois, os agentes do tráfico tentaram se apropriar do processo de pagar a conta de água no prédio. Silvio, que então "estava sofrendo a pressão", passou a se desviar o máximo que podia do gerente local para não entregar a lista com os nomes dos moradores-devedores. Seu receio era que aqueles que deviam o "dinheiro da água" fossem expulsos de seus apartamentos ou fossem cobrados de forma violenta. Outro medo compartilhado entre os moradores era o de que, ao controlar a conta de água, os membros do tráfico poderiam "vender" a água para os moradores do prédio a um preço acima do estipulado pela Cedae.

Com a ajuda de Leonor e de outras mulheres, eles criaram uma microestratégia de vigilância. Por meio de um grupo de whatsapp, eles enviavam mensagens sobre a movimentação do gerente local. Essas mensagens auxiliavam Silvio a não o encontrar. Embora algumas das novas famílias pagassem pelo consumo de água, Silvio tentava ao máximo não fazer um recibo do pagamento da água para que os novos moradores não utilizassem este papel como documento que comprovasse e regularizasse a habitação. Os meses foram passando, Silvio desviando. Após uma operação militar, o gerente do tráfico local foi assassinado por policiais militares, 
o que deixou os moradores aliviados. As tentativas dos membros do grupo de tráfico de drogas para se apropriarem dos recibos enfraqueceram. As novas famílias passaram a receber os recibos referentes ao pagamento da água e algumas delas iniciaram o processo de regularização da moradia.

As situações descritas acima nos permitem pensar nas formas com que os grupos armados entram nas tramas da vida cotidiana por meio das infraestruturas. Água, canos, boletos e recibos apresentam funcionalidades diferentes daquelas para as quais foram projetados. A expansão dos grupos armados através do controle de registros, contas e medidores fica no subterrâneo da discussão sobre o urbano e sobre a violência urbana. $O$ foco nas grandes violências e na produção das mortes oblitera como grupos armados expandem seu poder ao se infiltrarem nos ritmos da vida diária. Uma guerra não tradicional ocorre dentro da "Guerra" feita por invasões armadas, operações militares e tiroteios. Uma forma silenciosa de atuação dos grupos armados pela cidade se sedimenta nas tramas do cotidiano ao controlar as infraestruturas que garantem a vida. Os moradores da cidade que vivem em localidades dominadas por grupos armados assumem um "ceticismo incrustrado em uma vida amedrontada", ${ }^{5}$ cujas tramas são muito difíceis de serem desfeitas.

\section{Guerra de infraestrutura}

Dentre as obras urbanas projetadas para "revitalizar" o bairro, havia a reforma das tubulações públicas de água e esgoto. Eu frequentava semanalmente a casa de Leonor quando estavam sendo feitas as obras que ocorreram entre os anos de 2013 e 2016. Era difícil caminhar até o prédio com as ruas cheias de tratores, retroescavadeiras, os imensos buracos, as ruas enlameadas e a quase inexistência de iluminação pública. Oficialmente, a reforma nas tubulações prometia um maior fluxo de água e escoamento de esgoto para a região. Entretanto, as tubulações de grande parte dos imóveis eram antigas, algumas com mais de 70 anos que, sem estarem previstas no projeto de reforma, não tinham as infraestruturas necessárias para receber o novo volume de água. Durante a obra, houve períodos chuvosos e a água acumulava naqueles imensos buracos abertos nas ruas. As obras também impediram a vasão do esgoto. Nos meses chuvosos, a água que abastecia a região transbordava, misturava-se ao esgoto, chegava na cisterna da ocupação e, consequentemente, nas torneiras e nos chuveiros dos moradores. Isto não aconteceu uma, duas ou três vezes, ao contrário, cada vez que chovia se tornava um transtorno. 
Foram três anos de reforma que atormentaram a vida dos moradores da região. Nesse período, a falta de água era constante. Os moradores do bairro fizeram diversos protestos na sede da Cedae e reclamavam localmente com os engenheiros e os técnicos que trabalhavam na obra. Como resultado, a prefeitura enviou caminhões-pipa para encher as caixas d'água da ocupação, as escolas e outros imóveis. A água enviada era água de reúso, não potável para o consumo humano (ver Anand 2017b). A falta de água constante modificou os ritmos da vida diária de Leonor e de outros moradores da localidade. Mas a continuidade do abastecimento com água contaminada foi vivida de forma dramática: ela deixou de receber visitas em sua casa, pois "visita bebe água" e ela não tinha dinheiro para comprar água potável suficiente para ela, sua mãe e as visitas; ela passou a comprar água mineral, que afetava sua renda doméstica. $O$ fato de sua mãe ser bastante idosa e estar doente, fez com que Leonor utilizasse a água mineral para dar banho nela. O fornecimento público de água imprópria para beber ou cozinhar, portanto, é uma das formas de levar a "guerra infraestrutural" para dentro da casa das pessoas.

A ideia de "guerra infraestrutural" desenvolvida por Achille Mbembe (2003) em seu ensaio "Necropolítica" nos ajuda a refletir sobre os processos de produção da impossibilidade da vida por meio da destruição das infraestruturas que tornam as relações sociais possíveis. A guerra infraestrutural movida contra os moradores da ocupação durante a "revitalização" se deu através do abastecimento de suas casas com água contaminada, das tubulações abertas, do esgoto que permanecia no local, da ausência de luz, somada ao domínio do tráfico de drogas e às operações militares. Essas ações tornaram a vida "infernal" e incutiu nos moradores o desejo de deixarem o local. Enquanto o projeto oficial era transformar o bairro em um local de moradia para classe média, essas ações produziram exatamente o oposto. Os moradores da ocupação que tinham melhores condições financeiras deixaram o prédio, abrindo espaço para que mais famílias fossem introduzidas por intermédio do tráfico de drogas. E, ainda, justamente os moradores que viviam nas condições mais precárias foram os que reuniram forças para tornar a vida possível em meio aos escombros e permanecer na ocupação. Leonor foi uma delas.

Na mesma época em que as obras públicas nas tubulações ocorriam, membros do tráfico de drogas expulsaram o proprietário de um dos estabelecimentos comerciais localizados ao lado da ocupação e invadiram o local. Devido à escassez de água gerada pelas reformas nas tubulações, os jovens traficantes planejavam uma obra de infraestrutura. Quando canos, sacos de areia e cimento começaram a chegar no prédio, Leonor, Silvio 
e outros moradores passaram a trocar informações na tentativa de compreender o que estava acontecendo. Ao ouvir os rumores, eles entenderam que o acesso à água poderia estar em perigo. Eles souberam que o objetivo do grupo era retirar água da cisterna da ocupação para abastecer o imóvel comercial que se tornara um ponto de venda de drogas. Leonor, junto com outras mulheres, tentou contornar esta situação. Via whatsapp, ela me enviou mensagens pedindo que eu contatasse os advogados da Defensoria Pública para as auxiliarem neste problema. Na época, conseguimos este contato. Nas reuniões, eu expliquei a complexidade da questão aos defensores. Contudo, sem poder denunciar o que ocorria para a Polícia Militar e com a possibilidade de retaliações violentas contra os moradores, não conseguimos encontrar soluções para o problema.

No dia 2 de novembro de 2015, a obra que transferia a água da cisterna da ocupação para o novo ponto de venda de drogas foi terminada. Como a água que entrava na cisterna havia sido contabilizada pelo único medidor do prédio, toda a água consumida no estabelecimento comercial ao lado virava dívida para os moradores da ocupação. Quem cobraria a dívida do consumo de água dos membros do tráfico de drogas? Sem saída, os moradores viram o valor da conta de água aumentar e comprometer ainda mais o seu orçamento doméstico. Neste caso que durou cinco anos, vemos como grupos armados utilizam o dinheiro das pessoas que vivem em situações de pobreza e precariedade. A infraestrutura construída pelos membros do tráfico de drogas conecta materialmente o estado à vida privada dos moradores. Essa conexão feita por canos nos ajuda a compreender outras formas em que o trânsito entre o legal, o ilegal e o ilícito se faz na vida diária.

\section{Uma batalha infinita: considerações finais}

As batalhas pela habitação a que estão submetidos os pobres urbanos são, muitas vezes, invisíveis aos olhares externos e impensáveis mesmo para aqueles que vivem nesses espaços. Ainda assim, essas experiências podem ser vividas de forma dramática. Os esforços de Leonor para manter o abastecimento de água em sua casa está emaranhada à luta para garantir a continuidade dos ritmos e das rotinas de sua vida diária. Para construir e manter a rotina diante de um cotidiano marcado por instabilidades, Leonor se propôs a trabalhar como cobradora de água em diversos momentos da história da ocupação. Colocar-se em uma posição que gerava tantos conflitos e ameaças nos mostra a complexidade do processo de fazer a água circular em uma ocupação popular, que podemos ampliar para as diversas regiões da 
cidade que vivem com instabilidade o fornecimento de água e, nos últimos anos, com o abastecimento de suas casas com água escura, com gosto de barro e malcheirosa.

O ciclo mensal de consumo, dívida, cobrança e pagamento de água produziu relações específicas entre os moradores do prédio, mas também em relação ao estado e seu poder de cortar o abastecimento ou fornecer água imprópria para o consumo, e com grupos armados que disputavam este bem vital. Neste sentido, o ciclo mensal conecta o público e o privado, o estado e a vida íntima, e ainda enreda grupos criminais na vida daqueles que fizeram da ocupação a sua casa.

A experiência pessoal de Leonor se conecta com o trabalho coletivo feito pelos moradores da ocupação, na medida em que manter o abastecimento de água é também garantir a habitação como projeto político. Não se faz a vida sem água, e garantir a água é garantir a vida biológica, social e política neste e em outros lugares da cidade. Ao mesmo tempo, fazer a água circular no presente condensa toda a temporalidade das lutas passadas para acessar este bem vital. Os moradores da ocupação aprenderam a navegar pelas burocracias estatais, mesmo que ilegíveis e autoritárias, e pelas tênues linhas que separam e unem o legal, o ilegal e o ilícito no cotidiano.

Observar a potência do "frágil e minúsculo corpo humano" (Benjamin 1996) de Leonor no interstício dos poderes do estado e do tráfico de drogas nos ajuda a compreender como se deram as relações e os enfrentamentos que garantiram a permanência da ocupação. Diante das ameaças do tráfico e do estado, trazer o lugar das mulheres na tessitura dos conflitos nos mostra como as relações de gênero são fundamentais nos processos de fazer cidade. As escalas de problemas relacionados ao estado e ao tráfico de drogas que os moradores enfrentaram na luta para garantir que a água chegasse em suas casas surpreendiam mesmo aqueles que viviam na ocupação. A constante quebra de rotinas que os dois agentes em conjunto produziram na vida cotidiana pode ser pensada como parte da guerra infraestrutural (Mbembe 2003). Contudo, o trabalho manual feito por Leonor e por outras mulheres da ocupação para garantir o abastecimento de água tecia a vida social dentro do prédio. A agência de Leonor em face das condições que os criminalizavam e os tornavam ainda mais precários criou caminhos para a continuidade da ocupação, mesmo diante de situações tão estreitas. Foi o trabalho cotidiano de fazer a água circular que garantiu algum ritmo e uma certa rotina na vida social, e assim criou as condições para que os moradores permanecessem no prédio. 
Centrar as análises nas agências de pessoas comuns para se garantir o abastecimento de água nos revela as estruturas de poder que fazem a vida urbana e nos permite pensar como as desigualdades estão presentes nos ritmos e nas rotinas da vida cotidiana. Assim, defendo que uma "ordem urbana" pode ser produzida por meio do controle e da distribuição de um bem vital como a água, mas que podemos ampliar para as infraestruturas, de modo geral. Explorar a incerteza cotidiana com que a água é acessada pelas populações pobres nos mostra como as infraestruturas não são neutras, ao contrário, estão entranhadas em hierarquias de poderes que, ao mesmo tempo, obliteram e atualizam as desigualdades urbanas. Analisar as infraestruturas nos emaranhados de relações nos ajuda no trabalho de fazer o ordinário aparecer e recoloca a questão da produção da vida nas cidades por outros meios. Refletir sobre as grandes reformas urbanas que transformaram a cidade do Rio de Janeiro através das infraestruturas nos ajuda a capturar as formas com que as desigualdades foram atualizadas e vividas cotidianamente como "guerra" pelas populações pobres. Os caminhos que os moradores da Ocupação Nelson Mandela trilharam para acessar a água são, portanto, produtivos para pensarmos nas formas com que as populações pobres da cidade experienciam concretamente a vida urbana na qual as infraestruturas estão no centro das disputas.

Recebido em 30 de novembro de 2020

Aprovado em 20 de maio de 2021

Camila Pierobon é pós-doutoranda no Programa Internacional de Pós-Doutorado (IPP) do Centro Brasileiro de Análise e Planejamento (Cebrap); Doutora pelo Programa de Pós-Graduação em Ciências Sociais (PPCIS) da Universidade do Estado do Rio de Janeiro (UERJ). Suas áreas de interesse são: vida cotidiana, pobreza, gênero e habitação popular.

https://orcid.org/0000-0001-7590-0773

E-mail: camilapierobon@cebrap.org.br 


\section{Notas}

1 Este texto é um desdobramento dos debates ocorridos no Grupo de Estudos sobre Infraestrutura Urbana no âmbito dos grupos de pesquisa Casa (IESP/UERJ), do Urbano - Laboratório de Estudos da Cidade (PPGSA/UFRJ) e dos comentários recebidos no IPP/CEBRAP. Agradeço a todos os colegas que contribuíram para o avanço deste trabalho. Agradeço também à FAPESP pelo financiamento que permitiu a pesquisa. Processo 2018/15928-2.

2 No decorrer do texto utilizo o termo "batalha" em referência ao trabalho de Appadurai (2013). O autor emprega o termo com o objetivo de emaranhar as diversas escalas de problemas que as populações pobres precisam encarar para garantir a habitação. Para o autor, a batalha pela habitação deve levar em conta as intrincadas redes e arranjos sociais que conectam mercados, políticas, finanças, crime, arquitetura e especulação imobiliária. Appadurai ainda insere neste emaranhado os processos informais em que as comunidades humanas alocam seus recursos para garantir a moradia.

3 Há uma diversidade de formas com que os moradores se referem aos seus espaços de moradia: casa, apartamento, quitinete, quarto. No texto, uso todos os termos para valorizar o léxico dos moradores na classificação de suas casas.

$4 \mathrm{Na}$ descrição, pode parecer que estou reificando os lugares femininos ou masculinos na ocupação. Contudo, escolhi seguir a forma com que algumas mulheres construíram a memória desse início da ocupação e me narraram os conflitos. Para uma análise das acusações que recaíam sobre as mulheres nas ocupações, como "não limpar direito o prédio" ou "não cuidarem corretamente de seus filhos", ver Birman (2015); Fernandes (2013). Para uma análise sobre as acusações morais que recaem sobre os corpos femininos em favelas do Rio de Janeiro, ver Fernandes (2017).

5 Agradeço ao Marcos Campos pelos comentários feitos ao texto e por esta frase. 
Referências bibliográficas

ANAND, Nikhil. 2017a. Hydraulic City: water and infrastructures of citizenship in Mumbai. Durham: Duke University Press. . 2017b. "The Banality of Infrastructure". Items. Disponível em: https://items.ssrc.org/justenvironments/the-banality-ofinfrastructure/. Acesso em 09/07/2020.

APPADURAI, Arjun. 2013. "Housing and Hope". Places Journal. Disponível em: https://placesjournal.org/ article/housing-and-hope/?cn$\underline{\text { reloaded }=1 \# 0 .}$. Acesso em 09/07/2020.

APPEL, Hannah; ANAND, Nikhil \& GUPTA, Akhil. 2015. "The Infrastructure Toolbox. Theorizing the Contemporary". Cultural Anthropology website. Disponível em: https://culanth.org/fieldsights/725the-infrastructure-toolbox. Acesso em 09/07/2020.

ARAUJO, Marcella. 2017. Obras, casas e contas: uma etnografia de problemas domésticos de trabalhadores urbanos, no Rio de Janeiro. Tese de Doutorado, IESP/UERJ.

BARROS, Rachel. 2016. Urbanização e "pacificação" em Manguinhos: um olhar etnográfico sobre sociabilidade e ações de governo. Tese de Doutorado, IESP/UERJ.

BENMERGUI, Leandro \& GONÇALVES, Rafael Soares. 2019. "Urbanismo Miliciano in Rio de Janeiro". NACLA Report on the Americas, 51 (4):379385.

BENJAMIN, Walter. 1996. "Experiência e pobreza". In: Obras escolhidas: Magia e técnica, arte e política,. São Paulo: Editora Brasiliense. pp. 114-119.
BIRMAN, Patrícia. 2015. "Ocupações: territórios em disputa, gêneros e a construção de espaços comuns". In: Patrícia Birman; Márcia P. Leite; Carly Machado \& Sandra de Sá Carneiro (orgs.), Dispositivos urbanos e trama dos viventes: ordens e resistências. Rio de Janeiro: Editora FGV. pp. 163-186.

BIRMAN, Patrícia; FERNANDES, Adriana \& PIEROBON, Camila. 2014. “Um emaranhado de casos: tráfico de drogas, estado e precariedade em moradias populares". Mana, 20 (3):431-460.

BOYER, Dominic. 2015. "Anthropology electric". Cultural Anthropology, 30 (4):531-539.

BROWN, Stephanie. 2014. “Kampala's sanitary regime: whose toilet is it anyway?". In: Steve Graham \& Colin McFarlane, Infrastructural lives: urban infrastructure in context. London / New York: Routledge. pp. 153-172.

CAVALCANTI, Mariana. 2017. “Vida e morte do 'agrupamento 26': breve etnografia do Morar Carioca na 'Barra Olímpica' (2011-2013)". Revista de Antropologia, 60 (3):211-235.

CONCEIÇÃO, Wellington. 2016. Minha casa, suas regras, meus projetos: gestão, disciplina e resistências nos condomínios populares do PAC e MCMV no Rio de Janeiro. Tese de Doutorado, PPCIS/UERJ.

CORTADO, Thomas. 2018. À beira da cidade: política e poética da urbanização no Jardim Maravilha, "loteamento proletário" da Zona Oeste carioca. Tese de Doutorado, Museu Nacional/UFRJ. 
DAS, Veena. 2015. "What does ordinary ethics look like?" In: Michael Lambeck; Veena Das; Didier Fassin \& Webb Keane, Four lectures on ethics: anthropological perspectives. Chicago: HAU Books. pp. 53-125. . 2014. "Action, expression and everyday life: recounting household events". In: Michael D. Jakson; Arthur Kleinman; Bhrigupati Singh \& Veena Das (eds.), The Ground Between: Anthropologists engage philosophy. Durham: Duke University Press. pp. 279-306.

. 2007. Life and Words: violence and the descent into the ordinary. Los Angeles: University of California Press.

. 2004. "The signature of the state: The paradox of illegibility". In: Veena Das \& Debora Poole (eds.), Anthropology in the Margins of the State. Santa Fe: School of American Research Press. pp. 225-252.

DAS, Veena \& WALTON, Michael. 2015. "Political leadership and the urban poor: local histories". Current Anthropology. 56, Supplement 11:s44-s54.

DAVIES, Frank. 2017. Deodoro: formas de governo para uma "região olímpica". Tese de Doutorado, PPCIS/UERJ.

DESAI, Renu; McFARLANE, Colin \& GRAHAM, Stephen. 2014. "The politics of open defecation: informality, body and infrastructure in Mumbai". Antipode, 47 (1):98-120.

FERNANDES, Camila. 2017. Figuras da causação: sexualidade feminina, reprodução e acusações no discurso popular e nas políticas de Estado. Tese de Doutorado, Museu Nacional/ UFRJ.
FERNANDES, Adriana. 2013. Escuta ocupação: arte do contornamento, viração e precariedade no Rio de Janeiro. Tese de Doutorado, PPCIS/ UERJ.

FRANCO. Marielle. 2018. UPP - A redução da favela a três letras: uma análise da Política de Segurança Pública do Estado do Rio de Janeiro. São Paulo: N-1.

GRAHAM, Stephen; DESAI, Renu \& McFARLANE, Colin. 2013. "Water wars in Mumbai". Public Culture, 25 (1[69]):115-141.

GUPTA, Akhil. 2018. "The future in ruins: thoughts on the temporality of infrastructure". In: Nikhil Anand; Akhil Gupta \& Hannah Appel, The Promise of Infrastructure. Durham: Duke University Press. pp. 60-79.

GUTTERRES, Anelise dos Santos. 2016. "O rumor e o terror na construção de territórios de vulnerabilidade na zona portuária do Rio de Janeiro". Mana, 22 (1):179-209.

. 2014. A resiliência enquanto experiência de dignidade: antropologia das práticas políticas em um cotidiano de lutas e contestações junto a moradoras ameaçadas de remoção nas cidades sede da Copa do Mundo 2014 (Porto Alegre, RS e Rio de Janeiro, RJ/Brasil). Tese de Doutorado, PPGAS/UFRGS.

LANCIONE, Michele \& McFARLANE, Colin. 2016. "Infrastructural becoming: sanitation and the (un) making of life at the margins". In: Andres Blok \& Ignacio Farías (orgs.), Urban Cosmopolitics: agencements, assemblies, atmospheres. Questioning Cities. New York: Routledge. pp. 4562. 
LEITE, Márcia P. 2012. “Da 'metáfora da guerra' ao projeto de 'pacificação': favelas e políticas de segurança pública no Rio de Janeiro". Revista Brasileira de Segurança Pública, 6 (2):374-389.

LOBO, Heloísa. 2015. Processos de remoções e seus desdobramentos: tramas e percursos em busca de uma casa. Dissertação de Mestrado, PPCIS/UERJ.

MAGALHÃES, Alexandre. 2013. Transformaçóes no "problema favela" e a reatualização da remoção no Rio de Janeiro. Tese de Doutorado, IESP/ UERJ.

MBEMBE, Achille. 2003. "Necropolitics". Public Culture, 15 (1):11-40.

MENEZES, Palloma. 2015. Entre o "fogo cruzado" e o "campo minado": uma etnografia do processo de "pacificação" de favelas cariocas. Tese de Doutorado, IESP/UERJ.

MIAGUSKO, Edson. 2016. "Esperando a UPP: Circulação, violência e mercado político na Baixada Fluminense". Revista Brasileira de Ciências Sociais, 31 (91):1-15.

MUEHLMANN， Shaylih. 2019. "Clandestine Infrastructures: Illicit Connectivities in the US-Mexico Borderlands". In: Kregg Hetherington (ed.), Infrastructure, Environment, and Life in the Anthropocene. Durham: Duke University Press. pp. 45-65.

PIEROBON, Camila. 2018. Tempos que duram, lutas que não acabam: o cotidiano de Leonor e sua ética de combate. Tese de Doutorado, PPCIS/ UERJ.

PILO, Francesca, 2020. "Material Politics: Utility Documents, Claims-Making and Construction of the 'Deserving Citizen' in Rio de Janeiro". City \& Society, 0 (0):71-92.
QUINTSLR, Suyá. 2018. A (re)produção da desigualdade ambiental na metrópole: conflito pela água, "crise hídrica" e macrossistema de abastecimento no Rio de Janeiro. Tese de Doutorado, IPPUR/UFRJ.

RANGANATHAN, Malini. 2016. "Rethinking Urban Water (In) formality". In: Ken Conca \& Erika Wheintal (eds.), The Oxford handbook of water politics and policy. New York: Oxford University Press. pp. 1-18. . 2014. "'Mafias' in the Waterscape: Urban Informality and Everyday Public Authority in Bangalore". Water Alternatives, 7 (1):80-105.

ROITMAN, Janet. 2005. Fiscal Disobedience: an anthropology of economic regulation in Central Africa. Princeton: Princeton University Press.

SCHWENKEL, Christina. 2018. "The current never stops: intimacies of energy infrastructure in Vietnam". In: Nikhil ANAND; Akhil GUPTA \& Hannah APPEL (eds.), 2018. The promise of infrastructure. Durham: Duke University Press. pp. 102-132.

SCOTT, James. 1998. Seeing like a state: how certain schemes to improve the human condition have failed. New Haven: Yale University Press.

SILVA, Thamires L. 2017. Do invadir ao permanecer: experiências do habitar e precariedade numa invasão fabril no Complexo de Acari. Dissertação de Mestrado, PPCIS/UERJ.

SIMONE, AbdouMaliq. 2004. "People as Infrastructure: Intersecting Fragments in Johannesburg". Public Culture, 16 (3):407-419.

STAR, Susan Leigh. 1999. "The Ethnography of Infrastructure". American Behavioral Scientist, 43 (3):377-391 . 
TELLES, Vera. 2010. A cidade nas fronteiras do legal e ilegal. Belo Horizonte: Argvmentvm.

VALADARES, Lícia. 2005. A invenção da favela: do mito de origem a favela. com. Rio de Janeiro: FGV.

VIANNA, Adriana \& LOWENKRON, Laura. 2017. "O duplo fazer do gênero e do Estado: interconexões, materialidades e linguagem". Cadernos Pagu, 51 (1):e175101.

VON SCHNITZLER, Antina. 2016. Democracy's infrastructure: technopolitics and protest after apartheid. Princeton: Princeton University Press.

ZALUAR, Alba \& ALVITO, Marcos (orgs.). 2006. Um século de favela. 5. ed. Rio de Janeiro: Editora FGV. 
FAZER A ÁGUA CIRCULAR:

TEM PO E ROTINA NA BATALHA

PELA HABITAÇÃO

\section{Resumo}

Este artigo descreve os esforços de Leonor para garantir o abastecimento de água na ocupação popular onde vive. Seus esforços congregam a luta política dos ocupantes pelo direito de os pobres morarem no centro da cidade, a batalha das famílias para manterem os ritmos e a rotina de suas vidas diárias, e a guerra que envolve agentes do estado e do tráfico de drogas no cotidiano. O trabalho de Leonor está emaranhado ao trabalho coletivo de fazer a água circular nos 15 anos de existência da ocupação. Na primeira parte do texto, trago as ações dos moradores que transformaram um prédio abandonado em uma ocupação popular por meio da instalação, a regularização e a manutenção do abastecimento de água. Na segunda parte, apresento a batalha dos moradores nos interstícios dos poderes do estado e do tráfico de drogas em que a água potável estava no centro da disputa.

Palavras-chave: Água, Infraestrutura, Ocupação popular, Habitação, Gênero, Cotidiano, Tráfico de drogas, Estado.
FLOWING WATER:

TIME AND ROUTINE IN THE BATTLE FOR HOUSING

\section{Abstract}

This article describes Leonor's efforts to guarantee a steady water supply in the squat where she lives. Her efforts bring together the political struggle of occupiers for the right of the poor to live in the city center; the battle of families to keep the rhythm and routine of their daily lives; and the war that involves state agents and drug trafficking in everyday life. Leonor's work is entangled with the collective work of making water circulate throughout the fifteen years of the squat's history. In the first part of the article, I present the actions of residents who transformed an abandoned building into a squat through the installation, regularization and maintenance of the water supply. In the second part, I present the struggle of the residents at the interstices of the powers of the state and the drug trade, placing drinking water at the center of their disputes.

Keywords: Water, Infrastructure, Squat, Housing, Gender, Daily life, Drug trafficking, State 


\section{AGUA EN CIRCULACIÓN:}

\section{TIEMPO Y RUTINA EN LA BATALLA POR LA VIVIENDA}

\section{Resumen}

Este artículo describe los esfuerzos de Leonor para garantizar el suministro de agua en el asentamiento popular donde vive. Sus esfuerzos conjugan la lucha política de los ocupantes por el derecho de los pobres a vivir en el centro de la ciudad, la batalla de las familias por mantener los ritmos y la rutina de su vida diaria, y la guerra que involucra a los agentes del estado y el narcotráfico en su cotidiano. El trabajo de Leonor está imbricado con el trabajo colectivo de hacer circular el agua en los 15 años de existencia del asentamiento. En la primera parte del texto describo las acciones de los vecinos que transformaron un edificio abandonado en asentamiento popular mediante la instalación, regularización y mantenimiento del suministro de agua. En la segunda parte, presento la batalla de los vecinos en los intersticios de los poderes del estado y del narcotráfico en el que el agua potable fue el centro de la disputa.

Palabras-clave: Agua, Infraestructura, Asentamiento popular, Vivienda, Género, Vida diaria, Narcotráfico, Estado. 